\title{
Snakebite by the Shore Pit Viper (Trimeresurus purpureomaculatus) Treated With Polyvalent Antivenom
}

\author{
Rupeng Mong, MBBS; Hock Heng Tan, MBBS \\ From the Department of Emergency Medicine, Changi General Hospital, Republic of Singapore.
}

\begin{abstract}
Although snakebites are uncommon, there are several species of medically important venomous snakes native to Singapore. We present a case of envenoming by the shore pit viper (Trimeresurus purpureomaculatus) that showed clinical improvement when treated with the Indian (Haffkine) polyvalent antivenom. A 40-year-old man was bitten on his right hand by a snake, which was identified through photos and his description to be a shore pit viper, which is native to the local mangrove area. Severe swelling and pain developed immediately after the bite, which progressed up the arm. Because of the progression of local swelling, antivenom was started. He was given a total of 6 vials $(60 \mathrm{~mL}) \mathrm{of}$ polyvalent antivenom, with the first vial started 3 hours after the bite. He showed clinical improvement within 24 hours. His subsequent recovery was uneventful, with no other complications as a result of envenomation or antivenom use. Severe envenoming by the shore pit viper can lead to marked local effects such as extensive swelling and tissue necrosis. Antivenom is indicated in the presence of severe local envenomation. Antivenom against the shore pit viper is however not available locally. The Indian (Haffkine) polyvalent antivenom contains antibodies against 4 common venomous snakes in India, namely the Indian cobra, common krait, Russell's viper, and sawscaled viper. The improvement seen in this patient suggests possible cross-neutralizing activity of the Indian vipers' antivenom against the local shore pit viper venom. Further in vivo and in vitro studies should be performed to verify this clinical case.
\end{abstract}

Key words: snake, envenomation, shore pit viper, antivenom

\section{Introduction}

There are several species of medically important venomous snakes native to Singapore. They include the cobras (black spitting cobra, king cobra), vipers (shore pit viper, Wagler's pit viper), kraits (banded krait, Malayan krait), and coral snakes (blue and banded Malayan coral snake). ${ }^{1,2}$ However, specific antivenom for these species is not available for clinical use locally. We present a case of envenoming by the shore pit viper (Trimeresurus purpureomaculatus) that showed clinical improvement after treatment with the Indian (Haffkine) polyvalent antivenom. ${ }^{3}$

\section{Case Report}

A 40-year-old man presented to our hospital emergency department (ED) by ambulance 30 minutes after being

Corresponding author: Rupeng Mong, MCEM (UK), FAMS, Department of Emergency Medicine, Changi General Hospital, 2 Simei Street 3, Postal Code 529889, Republic of Singapore (e-mail: rupeng_mong@cgh.com.sg). bitten on his right hand by a snake in a mangrove area in Singapore at approximately 1530 hours. He had a past medical history of alcoholic liver cirrhosis, but was not intoxicated during this incident. He described the snake to be brown in color with no bands, approximately $1 \mathrm{~m}$ long, with a triangular-shaped head and red slit eyes. He had previous occupational experience handling snakes (worked in a zoo) and was trying to catch the snake for his amusement when the snake bit his hand. He immediately flung the snake away. It was later photographically identified to be a shore pit viper, which is endemic in that area. His right hand started swelling 10 minutes after the snakebite. There were no first aid measures including ligature application attempted at scene.

On initial clinical examination, there were 2 puncture wounds approximately $1 \mathrm{~cm}$ apart seen over the base of the middle finger on the dorsum of the right hand. There was no bleeding, but marked erythema and swelling surrounding the puncture marks was observed on the dorsum of his hand, extending to involve his digits (Figure 1). He had normal vital signs and no 


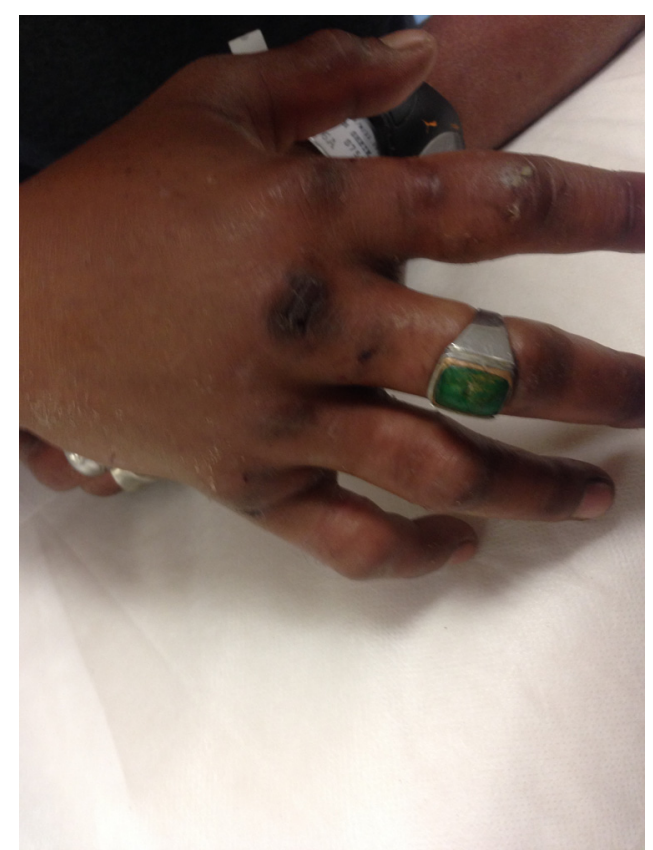

Figure 1. Swelling of hand on arrival (1 hour after bite).

neurological abnormalities. The ring on his middle finger was removed immediately. He was empirically started on antibiotics (amoxicillin/clavulanic acid, $1.2 \mathrm{~g} \mathrm{IV}$ ) and given tetanus toxoid. Titrated doses of morphine were administered in view of severe pain (a pain score of 9 of 10 on arrival).

The swelling of his hand progressed to involve his right forearm within the first 90 minutes of observation in the hospital, and there was no relief of pain despite being given $10 \mathrm{mg}$ of morphine. The toxicology service was consulted, and a decision was made to start antivenom. As antivenom for the shore pit viper is not available locally, the Haffkine polyvalent antivenom was used for this patient. He was given the first dose of antivenom (1 vial, $10 \mathrm{~mL}$ diluted in $250 \mathrm{~mL}$ of saline and infused over 2 hours) 3 hours after being bitten. Hydrocortisone $200 \mathrm{mg}$ IV and diphenhydramine $25 \mathrm{mg}$ IV were given just before its administration. The second dose of antivenom was administered approximately 2 hours after the first dose. The swelling, however, progressed proximally to involve his elbow and arm (Figure 2). Twelve hours after the injury, there was still progression of the swelling up his arm. During a period of 10 hours, he was given 4 further vials (total of $40 \mathrm{~mL}$ ) of antivenom.

Seventeen hours after the bite, there was no further progression of the swelling, and there was marked improvement in his pain. At 24 hours, there was reduction in the swelling, and the pain had mostly resolved. By 72 hours, most of the swelling had resolved

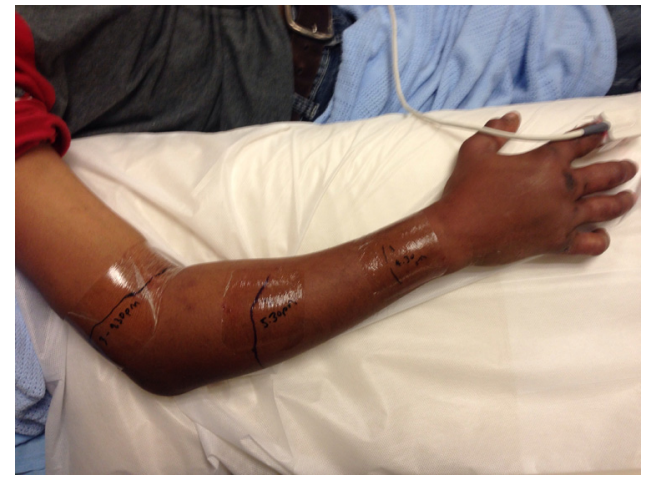

Figure 2. Progression of swelling (5 hours after bite).

(Figure 3). His subsequent recovery was uneventful. The time of antivenom administration, together with the progress of his condition and subsequent recovery, is summarized in the Table. There was no coagulopathy attributable to the incident; the patient had a history of thrombocytopenia secondary to liver cirrhosis.

\section{Discussion}

Snakebites are uncommon in Singapore, and epidemiological data are limited. The hospital that the patient presented to is a 700-bed tertiary hospital in the eastern region of Singapore, with approximately 150,000 ED attendances a year and staffed with emergency physicians. It runs a toxicology service that provides 24-hour availability for consultations by a toxicologist. A retrospective study of snakebites presenting to this hospital

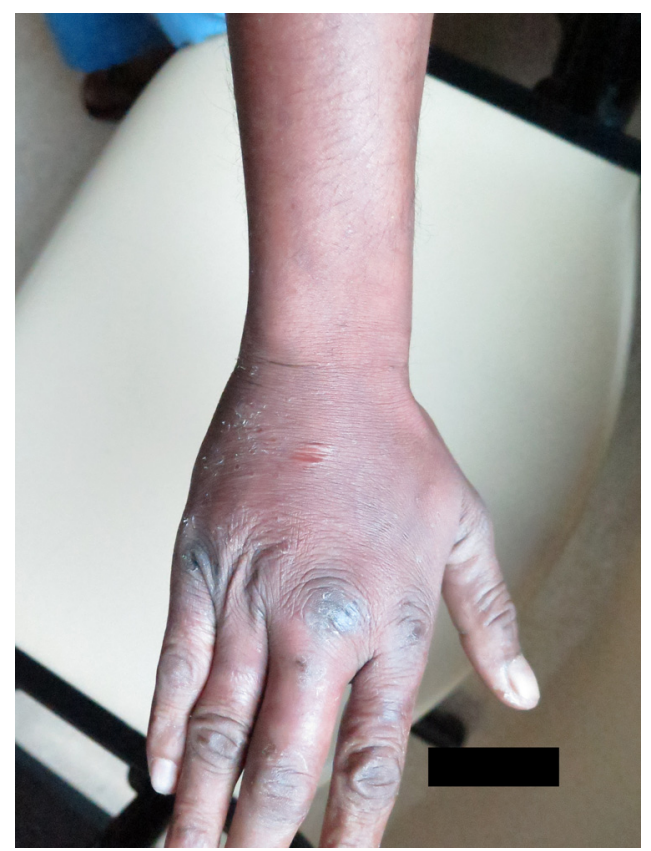

Figure 3. Resolution of swelling at 72 hours. 
Table. Timeline of events

\begin{tabular}{|c|c|c|c|c|c|c|c|}
\hline \multirow[b]{2}{*}{ Variable } & \multicolumn{7}{|c|}{ Time from bite } \\
\hline & $O h$ & $3 h$ & $5 h$ & $7 \mathrm{~h}$ to $16 \mathrm{~h}$ & $17 h$ & $24 h$ & $72 h$ \\
\hline Progress & $\begin{array}{l}\text { Immediate } \\
\text { swelling of } \\
\text { hand }\end{array}$ & $\begin{array}{l}\text { Swelling to } \\
\text { forearm }\end{array}$ & $\begin{array}{l}\text { Swelling to } \\
\text { elbow }\end{array}$ & $\begin{array}{l}\text { Swelling up } \\
\text { upper arm }\end{array}$ & $\begin{array}{l}\text { No further } \\
\text { progression } \\
\text { of swelling }\end{array}$ & $\begin{array}{l}\text { Marked } \\
\text { improvement } \\
\text { in swelling }\end{array}$ & $\begin{array}{l}\text { Swelling } \\
\text { mostly } \\
\text { resolved }\end{array}$ \\
\hline \multirow[t]{3}{*}{ Medication } & & $\begin{array}{l}1 \text { vial } \\
\text { antivenom }\end{array}$ & $\begin{array}{l}1 \text { vial } \\
\text { antivenom }\end{array}$ & $\begin{array}{l}4 \text { vials } \\
\text { antivenom }\end{array}$ & & & \\
\hline & Morphine $6 \mathrm{mg}$ & Morphine $2 \mathrm{mg}$ & Morphine $2 \mathrm{mg}$ & Morphine $4 \mathrm{mg}$ & & & \\
\hline & $\mathrm{IV}^{a}$ & IV & IV & $\mathrm{IV}^{a}$ & & & \\
\hline Pain score $(0$ to 10$)$ & 9 & 10 & 10 & 7 to 3 & 2 & 2 & 0 \\
\hline
\end{tabular}

${ }^{a}$ Given in titrated doses of $2 \mathrm{mg}$ IV.

showed a total of 52 cases recorded during a 5-year period. Most identified cases involved vipers and elapids, namely cobras, and there were no fatalities. ${ }^{1}$ The 2 main species of vipers in this region of Singapore include the shore pit viper (Figure 4$)^{2}$ and Wagler's pit viper. ${ }^{3}$ They can be differentiated from the black spitting cobra, which is black and raises its head with a hood when attacking. The shore pit viper is easily recognized by its triangular head, uniform purplish brown color, and slitlike red eyes; it is commonly found in the mangrove areas of Singapore. It is distinguished from the other pit viper, which has bands or is mainly greenish in color. Although the index snake was not caught, we were confident about the photographic identification by the patient because of the clinical presentation, the limited venomous local fauna, and the fact that the shore pit viper is a recognized native of the mangrove area.

Severe envenoming by the shore pit viper can lead to marked local effects such as extensive swelling and tissue necrosis, and systemic effects such as coagulopathy, bleeding, and hypovolemic shock. ${ }^{4}$ However, epidemiological data reported that serious envenomation was rare. ${ }^{5}$ Its venom demonstrated hemorrhagic, edemainducing, anticoagulant, and thrombinlike activities in

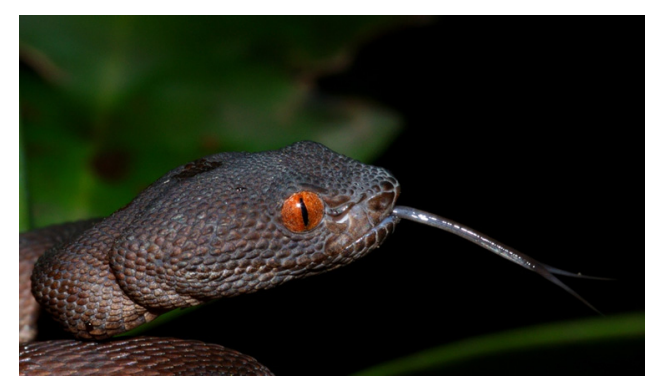

Figure 4. Picture of the shore pit viper from Singapore. Used by permission from Seshadri. ${ }^{2}$ animal studies. ${ }^{6}$ Although this patient did not demonstrate systemic features of toxicity, he likely suffered significant envenoming $^{7}$ as the swelling was extensive, with rapid progression to involve almost the entire arm, and the resultant pain from the bite was unremitting despite repeated doses of intravenous morphine. Antivenom is indicated in the presence of local envenoming that is rapidly progressing. ${ }^{7}$ When there are signs of local envenoming without systemic envenoming, as seen with this patient, antivenom is most effective if it is given within the first few hours after the bite. ${ }^{7}$ Case reports of shore pit viper envenomation are scarce, and epidemiological data provided little clinical data. ${ }^{5}$ Despite an extensive PubMed and web search, we found only 2 case reports. A welldocumented case report of a bite by the shore pit viper showed that without antivenom use, the local swelling and morbidity can take up to a week to resolve. ${ }^{8}$ The patient did not exhibit any systemic toxicity. In another report, presented as a scientific abstract, the patient also exhibited local swelling only and was given antivenom for Trimeresurus albolabris. He had rapid recovery within 1 to 2 days, suggesting possible cross-neutralization of the antivenom.

The Indian (Haffkine) polyvalent antivenom contains antibodies harvested using horse serum against 4 common venomous snakes in India, namely the Indian cobra (Naja naja), common krait (Bungarus caeruleus), Russell's viper (Vipera russelli), and sawscaled viper (Echis carinatus). ${ }^{10}$ It is used at our hospital for selected cases of severe envenoming. The antivenom for this patient was given slowly over 2 hours, and although 2 vials were recommended as the starting dose, only 1 vial was given initially by the treating physicians because of concern with adverse effects. As the swelling progressed, the antivenom was given 2 vials at a time. The recommended dosing of antivenom is quite varied even among different practitioners, with some recommending 
2 vials as a starting dose and others suggesting that 6 to 10 vials are needed. ${ }^{11}$ As the antivenom was not specifically targeted at the shore pit viper, the dosing of the antivenom in this case was empirical. It was fortunate that there was no adverse effect from the use of the antivenom in our patient, as reported rates of antivenom reactions after administration of the Haffkine polyvalent antivenom are as high as $55 \%$ and $88 \%$ in studies from Sri Lanka ${ }^{12}$ and Bangladesh, ${ }^{13}$ respectively. We are, however, not able to conclude whether the use of steroids or antihistamines, or the slow infusion of low-dose antivenom, contributed to this outcome, as previous studies have shown mixed results..$^{14,15}$

This is the first human report describing the use of the Haffkine polyvalent antivenom for shore pit viper envenomation. Apart from animal studies with the black spitting cobra, ${ }^{16}$ its efficacy against other local species has not been described. Cross-neutralization studies have shown efficacy of various antivenom against different species of elapids and vipers. In one study, the Vins polyvalent antivenom from India, which contains antibodies against the same 4 snake species as the Haffkine antivenom, showed in vitro cross-neutralization activity against several species of Asiatic cobras, the king cobra (Ophiophagus hannah) and the Malayan krait (Bungurus candidus). ${ }^{17}$ The Thai Red Cross Hemato-polyvalent antivenom, which has antivenom raised against Calloselasma rhodostoma, Trimeresurus albolabris, and Daboia siamensis, showed cross-neutralization activity against several other species of Asian vipers (Trimeresurus purpureomaculatus, Popeia popeorum, Hypnale hypnale) in experimentally envenomed mice. ${ }^{18,19}$ Isbister et $\mathrm{al}^{20}$ reported a snakebite victim from Nepal likely envenomed by an Asian pit viper who was treated successfully with the Thai Hemato-polyvalent antivenom and the Antivipmyn antivenom, which has antivenom raised against Crotalus durissus and Bothrops asper. The Haffkine polyvalent antivenom had also shown fair cross-reactivity to 2 species of Indian Trimeresurus pit vipers in animal studies. ${ }^{21}$ Cross-neutralization studies are important as antivenom production is expensive and only available for certain species of snakes. The improvement seen in this patient suggests that there may be cross-neutralizing activity of the Indian vipers' antivenom against the local shore pit viper venom. Further in vivo and in vitro studies should be performed to verify this clinical case.

\section{Conclusions}

The Indian (Haffkine) polyvalent antivenom demonstrated clinical efficacy in the treatment of envenoming by local shore pit viper in our patient. However, further studies are needed to verify the efficacy before the antivenom can be recommended as a standard of care for envenomation by the shore pit viper.

\section{Acknowledgments}

The authors would like to thank Professor P. Gopalakrishnakone, from the Venom and Toxin Research Group, National University of Singapore, for his comments and suggestions in the writing of this case report.

\section{References}

1. Tan HH. Epidemiology of snakebites from a general hospital in Singapore: a 5-year retrospective review (2004-2008). Ann Acad Med Singapore. 2010;39: 640-647.

2. Seshadri KS. Shore pit viper from Singapore. Licensed under CC BY-SA 3.0 via Commons. Available at: https:// commons.wikimedia.org/wiki/File:Shore_pit_viper_from_ Singapore.jpg/media/File:Shore_pit_viper_from_Singapore. jpg. Accessed February 23, 2016.

3. Gopalakrishnakone P, Chou LM, Maung MA, Lim LK. Dangerous snakes. In: Gopalakrishnakone P, ed. A Colour Guide to Dangerous Animals Singapore: Singapore University Press; 1990.

4. White J. Viperid snakes. In: Dart RC, ed. Medical Toxicology. 3rd ed. Philadelphia, PA: Lippincott Williams \& Wilkins; 2003:1579-1591.

5. Reid HA, Thean PC, Artin WJ. Epidemiology of snake bite in north Malaya. BMJ. 1963;1:992-997.

6. Tan NH, Tan CS. Biological properties of Trimeresurus purpureomaculatus (shore pit viper) venom and its fractions. Toxicon. 1988;26:989-996.

7. [No authors listed]. WHO/SEARO Guidelines for the clinical management of snake bites in the Southeast Asian region. Southeast Asian J Trop Med Public Health. 1999;30(suppl 1):1-85.

8. Frith CW, Frith DB. A case of snake bite by the shore pit viper, Trimeresurus purpureomaculatus (Viperidae). Nat History Bull Siam Soc. 1975;26:159-163.

9. Suteparuk S. A case of shore pit viper (Trimeresurus purpureomaculatus) bite treated with antivenom for Trimeresurus albolabris. Poster presentation at Asia Pacific Association of Medical Toxicologists 12th International Scientific Congress; 2013.

10. Haffkine snake antiven. Available at: http://www.vaccine haffkine.com/products/antitoxins-sera/snake-antivenin-de tail.html. Accessed February 23, 2016.

11. Simpson ID, Norris RL. Snake antivenom product guidelines in India: "the devil is in the details.". Wilderness Environ Med. 2007;18:163-168.

12. Seneviratne SL, Opanayaka CJ, Ratnayake NS, et al. Use of antivenom serum in snake bite: a prospective study of hospital practice in the Gampaha district. Ceylon Med J. 2000;45:65-68. 
13. Amin MR, Mamun SMH, Rashid R, et al. Anti-snake venom: use and adverse reaction in a snake bite study clinic in Bangladesh. J Venom Anim Toxins Incl Trop Dis. 2008;14:660-672.

14. Gawarammana IB, Kularatne SA, Dissanayake WP, Kumarasiri RP, Senanayake N, Ariyasena H. Parallel infusion of hydrocortisone +/- chlorpheniramine bolus injection to prevent acute adverse reactions to antivenom for snakebites. Med J Aust. 2004;180:20-23.

15. de Silva HA, Pathmeswaran A, Ranasinha CD, et al. Low-dose adrenaline, promethazine, and hydrocortisone in the prevention of acute adverse reactions to antivenom following snakebite: a randomised, double-blind, placebo-controlled trial. PLoS Med. 2011;8(5):e1000435.

16. Cham G, Lim F, Earnest A, Gopalakrishnakone P. Crossreactivity against Naja sumatrana (black spitting cobra) envenoming from the Haffkine antivenom in a mouse model. ISRN Toxicol. 2013;2013:247645.
17. Leong PK, Tan NH, Fung SY, Sim SM. Cross neutralisation of Southeast Asian cobra and krait venoms by Indian polyvalent antivenoms. Trans $R$ Soc Trop Med Hyg. 2012; 106:731-737.

18. Leong PK, Tan CH, Sim SM, et al. Cross neutralization of common Southeast Asian viperid venoms by a Thai polyvalent snake antivenom (Hemato Polyvalent Snake Antivenom). Acta Trop. 2014;132:7-14.

19. Tan CH, Leong PK, Fung SY, et al. Cross neutralization of Hypnale hypnale (hump-nosed pit viper) venom by polyvalent and monovalent Malayan pit viper antivenoms in vitro and in a rodent model. Acta Trop. 2011;117:119-124.

20. Isbister GK, Maduwage K, Page CB. Antivenom cross neutralisation in a suspected Asian pit viper envenoming causing severe coagulopathy. Toxicon. 2014;90:286-290.

21. Kankonkar RC, Rao SS, Vad NE, Sant MV. Efficacy of Haffkine Institute polyvalent antivenin against Indian snake venoms. Indian J Med Res. 1972;60:512-516. 